\title{
WHY AND HOW INDO-MEDITERRANEAN DIET, MAY BE SUPERIOR TO OTHER DIETS? THE ROLE OF ANTIOXIDANTS IN THE DIETS
}

\author{
Ram B Singh ${ }^{1}$, Ghizal Fatima ${ }^{2}$, Jan Fedacko ${ }^{3}$, Aminat Magamadov ${ }^{4}$, Shaw Watanabe ${ }^{5}$ \\ ${ }^{1}$ Halberg Hospital and Research Institute, Moradabad, India; rbs@tsimtsoum.net \\ ${ }^{2}$ Era's Lucknow Medical College and Hospital, Lucknow, India; ghizalfatima8@gmail.com \\ ${ }^{3}$ Research Park, PJ Safaric University, Kosice, Slovak Republic, janfedacko@ hotmail.com \\ ${ }^{4}$ Lomonov University, Moscow, Russia; amgerma@gmail.com \\ ${ }^{5}$ Life Science Association, Tokyo, Japan; watashaw@medicalrice.com
}

\section{Correspondence:}

Dr Shaw Watanabe, MD, PhD

Life Science Association,

Tokyo,

Japan; watashaw@medicalrice.com

\begin{abstract}
The Seven Country study showed that traditional Japanese diet and Mediterranean diets are protective against cardiovascular diseases (CVDs). Japanese diet is considered the healthiest because it provides highest longevity and health to Japanese. DASH diet and Mediterranean style diets are also considered the healthy diets, although, it is possible that Indo-Mediterranean style diet may provide better protective effects among patients with CVDs, compared to other diets. The concept of Indo-Mediterranean type of diets was developed, after examining its role in the prevention of CVDs in India, the value of which was confirmed by a landmark study from France; The Lyon Heart Study. These workers found that eating alpha-linolenic acid rich Mediterranean style diet can cause significant decline in CVDs and all-cause mortality. Later on in 2018, PREDIMED Study from Spain also reported that a modified Mediterranean style diet can cause significant decline in CVDs, type 2 diabetes mellitus (T2DM) and cancer. The IndoMediterranean diet may be superior to DASH diet and Mediterranean diet because it contains millets, porridge, beans and spices; turmeric, cumin, fenugreek and coriander which may have better anti-inflammatory and cardio-protective effects. These foods are rich sources of nutrients; flavonoids, calcium and iron as well as proteins which are useful in the prevention of under as well as over-nutrition and related diseases. It is known that DASH diet and Mediterranean style diets have similar influence on CVDs. However, Indo-Mediterranean style diet, may be as good as Japanese diet, due to improved food diversity and high content of antioxidants in the diets.
\end{abstract}

Key Words: Mediterranean diet, DASH diet, vegetables, fruits, hypertension, diabetes. 


\section{INTRODUCTION}

The Seven Country Study was the first to observe that people of Japan and the Mediterranean countries enjoy a low risk of cardiovascular disease (CVDs), which may be due to cardioprotective effects of these diets [1-3]. The UNO in 1998 also certified that Japanese diet could be a crucial factor for their longevity and healthy life expectancy. In Mediterranean countries such as Greece, Southern Italy and Spain, people consume traditional Mediterranean diet which is protective against CVDs, diabetes and cancer [4]. Apart from these diets, a DASH diet has also been developed and found protective against CVDs [5,6]. It seems, that there are both similarities and discrepancies in the consumption of foods and nutrients intake, in particular antioxidant intakes, which could be determinant of effectiveness of these diets [3,4]. A traditional Japanese diet shares several similarities with a traditional Mediterranean diet, based on a foundation of plant foods. Rice, vegetables, grains, legumes and fruit; fish is consumed regularly, more in Japan than Mediterranean countries, but red meat more sparingly. The majority of fat consumed in Japan is rice bran oil, whereas in Mediterranean countries, its olive oil and from unsaturated sources $[3,4]$. It has been found that all the special types of diets may safe guard against the risk of CVDs and type 2 diabetes mellitus (T2DM) [4-8]. The Japanese diet is naturally rich in fish, seaweed, green tea, soy, fruits, and vegetables but low in added sugar, fat, and other animal protein. However, the main features of the Indo-Mediterranean diet are higher in whole grains, spices and mustard oil, apart from fruits and vegetables and fish to non-vegetarians. The Indo-Mediterranean diet has been found protective against CVDs [7-10]. It is proposed that whole grain content, in particular antioxidants in various diets may explain, at least in part, the differences in cardio-protective potential of these diets. This article aims to highlight the differences in the efficacy of these diets.

\section{COMPARISON OF VARIOUS TYPES OF HEALTHY DIETS}

Epidemiological studies, including cross-sectional surveys, long-term prospective observational studies and short-term trials of intermediate outcomes, have provided supporting evidence that western type diets have adverse effects whereas diets rich in nutrients with modest amount of fish are protective against CVDs, T2DM and cancer [1,11-16]. Al of the high-quality diets are characterized with unrefined, unprocessed or minimally processed foods with high glycemic index, The major differences in various type of diets are determined by several food items such 
as fruits, vegetables, nuts fish, vegetable oils which are beneficial and rich in nutrients. However, western type of foods; refined and fast foods, syrups, red meat, processed meat, and trans fat, have been found to have potential causal relationships between specific dietary factors and NCDs (coronary artery disease, diabetes, and colorectal cancer [1,16-18]. The Japanese and the Mediterranean diet as well as DASH diet are known to be healthy [4-6,18]. The populations in the Mediterranean countries have a lower risk of CVDs, T2DM and cancer, which is similar to Japanese populations who are known for longevity as well as healthy life expectancy $[3,17,18]$. The Mediterranean diet is characterized with greater consumption of whole grains, (wheat), fruits and vegetables, along with olive oil and fish $[4,17,18]$. The DASH diet has some similarity with Mediterranean diet, because it also contains, more vegetables, nuts, whole grains, fish with low refined foods and low red and preserved meat and poultry, without emphasis on olive oil $[5,6]$. Japanese also consume large amounts of whole grains (rice), vegetables, fruit, and fish, but there is much lower intake of energy from oils and fats $[3,17,18]$. The traditional Mediterranean diet includes high amounts of total fats (80-100 g/day) with $40 \%$ of energy from polyunsaturated fatty acids (PUFAs) in males, with high proportions of monounsaturated fatty acids (MUFAs), largely from olive oil and nuts [4,17,18]. However, the typical Japanese diet has been characterized with lower consumption of total fats (15-20\% energy K calories/day), including saturated fatty acids, MUFAs and PUFAs, particularly of n-6 PUFAs [3,17,18]. Interestingly, in the last 2-3 decades, there has been a change from $20 \%$ energy from fats to $30 \%$, whereas the ratio of n-6 PUFAs/n-3 PUFAs has shifted from 2-3 to 4-5 [1-3, 17, 18]. It is possible that these alterations in the Japanese dietary patterns may enhance the risk of CVDs and T2DM in Japan. There is an unmet need to find out the effects of changes in the concentrations of fatty acids and western type foods and nutrients in the Japanese diets on health and risk of CVDs [11,12]. The differences in various types of high quality diets are shown in the Table 1.

Table 1: Comparison of Indo-Mediterranean diet with other scientific diets

\begin{tabular}{|l|l|l|l|l|}
\hline Foods & Indo-Mediterranean & Mediterranean & DASH diet & Japanese diet \\
\hline Vegetables, fruits & 400 g/day & High & High & High \\
\hline Nuts & $50-100$ g/Day & High & Moderate & Low \\
\hline $\begin{array}{l}\text { Whole grains, } \\
\text { beans }\end{array}$ & $\begin{array}{l}400 \text { g/Day, High; beans } \\
\text { millets, porridge, }\end{array}$ & $\begin{array}{l}\text { Moderate, } \\
\text { legumes }\end{array}$ & $\begin{array}{l}\text { Moderate, } \\
\text { legumes }\end{array}$ & $\begin{array}{l}\text { High rice, soya } \\
\text { bean- tofu. }\end{array}$ \\
\hline
\end{tabular}




\begin{tabular}{|c|c|c|c|c|}
\hline & grams, soybean. & & & \\
\hline Vegetable oil & $\begin{array}{l}30-80 \mathrm{~g} / \text { Day, Mustard } \\
\text { oil or blend of olive oil. }\end{array}$ & $\begin{array}{l}\text { Olive oil, } \\
\text { High(100g/day) }\end{array}$ & $\begin{array}{l}\text { Low saturated } \\
\text { fat foods,oils }\end{array}$ & $\begin{array}{l}\text { Low, rice bran } \\
\text { oil }\end{array}$ \\
\hline Fish & 100-150 g, twice/week & Moderate & Moderate & High, raw \\
\hline Dairy products & Butter Milk and Curd & Low fat & Low fat & Low \\
\hline Wine & No advise but allowed & Moderate & No advise & Sake-rice wine \\
\hline $\begin{array}{l}\text { Spices; Coriander, } \\
\text { cumin, turmeric, } \\
\text { cloves, cardamom. }\end{array}$ & $\begin{array}{l}\text { High (50-15o g/day), } \\
\text { Coriander, cumin, } \\
\text { turmeric, fenugreek }\end{array}$ & No advise & No advise & No advise \\
\hline Poultry & No advice & Moderate & Low & Low \\
\hline Red meat & No advice & Low & Low & Low \\
\hline Preserved meat & No advice & Low & No advise & Low \\
\hline Sweets and sugar & No advice & Low & Low & Low \\
\hline Nutrients & $\begin{array}{l}\text { High flavonoids, fiber, } \\
\mathrm{K}, \mathrm{Mg}, \mathrm{Ca} \text {, iron, } \\
\text { proteins. }\end{array}$ & $\begin{array}{l}\text { No specific } \\
\text { advice for } \\
\text { protein. }\end{array}$ & $\begin{array}{l}\text { High } \mathrm{K}, \mathrm{Mg} \text {, } \\
\text { Ca, fiber \& } \\
\text { protein, }\end{array}$ & $\begin{array}{l}\text { High in } \mathrm{n}-3, \mathrm{~K}, \\
\mathrm{Mg}, \mathrm{Ca} \text {, high } \\
\text { protein. }\end{array}$ \\
\hline Food diversity & Marked & Moderate & Moderate & Moderate \\
\hline Glycemic index & Very low & Lower & Lower & Very low \\
\hline
\end{tabular}

$\mathrm{K}=$ potassium, $\mathrm{Mg}=$ Magnesium, $\mathrm{Ca}=\mathrm{Calcium}, \mathrm{n}-3=$ Long chain omega- 3 fatty acids.

Indo-Mediterranean style diets differs because it has more of whole grains; in particular, millets, porridge, green beans and a variety of healthy spices such as turmeric, coriander, cardamom, cinnamon, cumin, black peppers, clove etc, It is possible that this diet can prevent the double burden of diseases due to undernutrition as well as over-nutrition.

\section{ANTIOXIDANTS IN FOODS OF VARIOUS DIETS}

Any agent with the capacity to either scavenge the free radicals or prevent the generation of prooxidant molecules, such as reactive oxygen species (ROS) may be called the antioxidants [20]. In human and animal tissues, the main source for ROS production is the mitochondria, which can generate singlet oxygen (1O2), superoxide radicals (O2 •-) or hydrogen peroxide [15,20,21]. 
However, in plants, chloroplast is the most important organelle to produce ROS. Each cell in the tissues and organs has its own antioxidant machinery to quench the deleterious effects of their internal ROS levels and its production. Catalase, super-oxide-dismutase (SOD), glutathione peroxidase (GPS) and ceruloplasmin are the most powerful natural antioxidants produced in the body for protection against ROS [20]. Decreased intake of minerals; iron, zinc, selenium and copper may worsen the deficiency of these antioxidants, because these minerals are required for their synthesis [21]. Apple, grapes, watermelon, orange, guava and green leafy vegetables are rich sources of antioxidant nutrients such as vitamins $\mathrm{A}, \mathrm{C}$ and $\mathrm{E}$, and the minerals copper, zinc and selenium, beta-carotene, lutein, and lycopene $[11,12,15]$. Whole grains are rich sources of magnesium, calcium, minerals, and all beans provide adequate proteins. Fruits vegetables, nuts and whole grains are all rich in flavonoids $[2,11,12,20,21]$

\section{Flavonoids in the Foods and Diets}

Flavonoids, flavones, catechins, polyphenols, anthrocyanins, lignans and phytoestrogens are all types of antioxidants and phytonutrients, and they are all found in plant-based foods [20,21]. There are more than 4,000 known flavonoids which are just one class of antioxidants. Diets rich in fruits such as berries; blackberries, cranberries, strawberries or blueberries and berries of all kinds are richest sources of antioxidant nutrients, in particular anthocyanins [15]. Anthrocyanins are also from the flavonoids group which are pigments widely distributed in fruits and vegetables [20]. Anthrocyanins are responsible for red, blue, purple, and yellow colors in fruits, flowers, and vegetables and protect plant cells from environmental stresses such as high sunlight and pollutants [21]. In a recent study on flavonoid content of foods, blueberries and lingonberries were found to contain higher contents of flavonoids (1100 mg/100 g dry weight) than raspberries and strawberries (500 mg/100 g dry weight). Anthocyanins were the dominant flavonoids in all berries [22]. This analysis reported compounds to contribute 18\%, 29\%, 61\%, and 67\% of the total flavonoid content in strawberries, lingonberries, raspberries, and blueberries, respectively. In eastern and western societies, respectively tea, coffee, cocoa and wine are the primary dietary sources of flavonoids. Apart from, leafy vegetables, onions, apples, berries, cherries, soybeans, and citrus fruits are considered an important source of dietary flavonoid [15,20-30]. 
USDA has been the first to release a database on the flavonoid content of foods in 2003 , which was updated using new data on 20 different flavonoids from a nationwide sampling of 59 fruits, nuts and vegetables, and 102 scientific papers [23]. The new database contains data on flavonoid for 395 food items and data from the National Health and Nutrition Examination Survey to ascertain the intake of five classes of flavonoids: anthocyanidins, flavanones, flavonols, flavones, and flavan-3-ols on a population basis (www.ars.usda.gov/nutrientdata). Interestingly, black tea provided the largest amount of flavonols to the diet (32\%), followed by onions $(25 \%)$ and parsley was the largest contributor of flavones. Dried parsley leaves contain a large amount; $13.53 \mathrm{~g} / 100 \mathrm{~g}$, though rarely is $100 \mathrm{~g}$ consumed at one time; a teaspoon weighs $0.5 \mathrm{~g}$. Among fruits; oranges (53\%) and grapefruit juice (16\%) contributed significant amounts of the flavanones. Brewed tea provides the largest quantities of flavan-3- ols to the diet. Blueberries contributed the largest amount of anthocyanidins (31\%), followed by bananas (21\%) and strawberries (14\%). Athough bananas contain lower amount of anthocyanidins than any of the berries, but the intake of bananas is much higher than that of individual berries. This database provides word-wide researchers with new values on the flavonoid content of many more foods in order to better ascertain the impact of flavonoid consumption in various diseases [23].

Daily per capita intake of flavonoids in the United States, using these data was: anthocyanidins, $5 \mathrm{mg}$; flavanones, $4 \mathrm{mg}$; flavones, $1 \mathrm{mg}$; flavonols, $10 \mathrm{mg}$; and flavan-3-ols, 112 $\mathrm{mg}$, total intake $132 \mathrm{mg} /$ day. This is too low compared to estimated flavonoid intake in European (250-900 mg/day), Asian (200-650 mg/day), and in the middle east countries, $1650 \mathrm{mg} /$ day) [15]. The higher intake of flavonoids in these countries, is because of mainly black tea $[23,28,29]$. In the Indo-Mediterranean diet, the flavonoid intake was $1800 \mathrm{mg} / \mathrm{day}[7,9,10]$. Despite the high intake of fruits, vegetables, and red wine in Mediterranean countries, the intake of total flavonoids in these countries (250-400 mg/day) is lower than in other European countries (350-900 mg/day), which is due to the much higher consumption of tea in non-Mediterranean countries [29]. In Japan, the mean intake of total flavonoids; flavan-3-ols, isoflavones, flavonols, flavanones and flavones was approximately $1500 \mathrm{mg} /$ day, mainly from green tea, soya foods, onion, leafy vegetables and fruits [30]. Thus the total flavonoid in the Japanese diet is comparable with flavonoid contents in the Indo-Mediterranean diet (1500 verses $1800 \mathrm{mg} / \mathrm{day}$ ), respectively, which make these diets potential source of flavonoid consumption, for cardiometabolic protection $[7,30]$. 


\section{Flavonoid Intake and Risk of Cardiovascular Diseases}

Flavonoids are polyphenolic plant metabolites that have biologically relevant protective effects in a number of cardiometabolic disorders(CMDs) [24]. Some of the epidemiological studies underscored a negative association between dietary flavonoid consumption and the propensity to develop CMD, which indicated that the contribution of the gut microbiota may be crucial, for metabolizing dietary intake as it relates to CVDs [24]. The Seven Countries Study showed that flavonoid intake at baseline around 1960, was estimated by flavonoid analysis of equivalent food composites of the diets, in the 16 cohorts [2]. After follow up of 25 years, mortality from CAD, cancer (various sites), and all causes in the 16 cohorts revealed that average consumption of antioxidant flavonoids was inversely associated with CAD mortality. The study also explained about $25 \%$ of the variance in the rates of CAD in the 16 cohorts. The consumption of saturated fat $(73 \% ; \mathrm{P}=0.0001)$, flavonoid intake $(8 \%, \mathrm{P}=.01)$, and percentage of smokers per cohort $(9 \% ; \mathrm{P}=.03)$ explained together, independent of intake of alcohol and antioxidant vitamins, $90 \%$ of the variance in the rates of CAD. Interestingly, consumption of flavonoid was not independently associated with mortality from other causes. It is clear from this study, that average consumption of flavonoid may partly contribute to differences in mortality due to CAD, across populations, but it did not seem to be an important determinant of cancer mortality in this study [2].

In a systemic review, a total of 39 prospective cohort studies are included, comprising 1501 645 subjects and a total of 33637 cases of CVD, 23664 of CAD, and 11860 of stroke [25]. Increased intake of total dietary flavonoids was linearly associated with a lower risk of CVD. Among the main classes of flavonoids, increasing intake of anthocyanins and flavan-3-ols is inversely associated with risk of CVD, while flavonols and flavones with CAD. Only increasing flavanones showed a linear inverse association with stroke risk. Catechins showed a favorable effect toward all outcomes of CVDs [25]. The intake of quercetin and kaempferol was also linearly associated with lower risk of CAD and CVD, respectively. However, higher intake of all the aforementioned compounds was associated, with a various extent, with a lower risk of CVD when considering comparison of extreme categories of consumption. It seems that a flavonoid rich diet may be of potential cardiovascular benefits [25]. 
In another systemic review, at least 27 prospective cohorts (in 44 publications) have evaluated the association between estimated habitual flavonoid intake and CVD risk [26]. The totality of evidence suggested that a long-term intake of flavonoid-rich foods may be associated with a lower risk of fatal and non-fatal CAD, CVD, with total CVD; outcomes. The type of flavonoid subclasses were more often included diets rich in anthocyanins, flavan-3-ols, and flavonols in lowering the risk of CVDs [26]. In the Nurses’ Health study (1'990-2018), among 60, 582 women, and Health Professional follow up study (1990-2018) including 31,801 men, the follow up period was 28 years [27]. After follow up, 36,856 deaths occurred. The multivariableadjusted pooled HR for all-cause mortality among participants who had the highest consumption of olive oil (>0.5 tablespoon/day or $>7 \mathrm{~g} / \mathrm{d}$ ) was 0.81 (95\% CI: 0.78-0.84) compared with those who never or rarely consumed olive oil. The consumption of greater amount of olive oil was associated with 19\% lower risk of CVDs mortality (HR: 0.81; 95\% CI: 0.75-0.87), 17\% lower risk of cancer mortality (HR: 0.83; 95\% CI: 0.78-0.89), 29\% lower risk of neurodegenerative disease mortality (HR: 0.71; 95\% CI: 0.64-0.78), and $18 \%$ lower risk of respiratory disease mortality (HR: 0.82; 95\% CI: 0.72-0.93). Replacement of $10 \mathrm{~g} / \mathrm{d}$ of margarine, butter, mayonnaise, and dairy fat with the equivalent amount of olive oil was associated with $8 \%-34 \%$ lower risk of total and cause-specific mortality [27]. Interestingly, no significant associations were observed when olive oil was compared with other vegetable oils combined, indicating that it is flavonoid content of olive oil that has provided the benefits.

In a previous systemic review, total polyphenol intake for the overall population was estimated to be about $900 \mathrm{mg} / \mathrm{day}$; which varied according to differences in target groups of subjects [28]. The main food sources of polyphenols were; vegetables, fruits, tea, coffee and red wine. The intake of total flavonoids and specific subclasses, but not total polyphenols, have been observed to be associated with a low risk of diabetes, CVDs and all-cause mortality. Despite several variations in the data available, it seems that the protective effect of a polyphenol-rich dietary pattern need further studies which should be encouraged in order to define specific therapy [28]. Interestingly, this review reported a higher intake of flavonoids compared to other studies [15,20-29];12 studies found an inverse association between polyphenol intake and CV events [28]. In some studies, a significant decreased CV risk was observed at the highest quartile of total polyphenol intake (1170 mg/day for Spain and $2632 \mathrm{mg} /$ day for Poland) [28,31,32]. However, other studies performed in Spain and Iran (1248 mg/day and $2459 \mathrm{mg} /$ day $)$ 
respectively, reported no benefits, which may be due to no substantial differences in the interindividual intake of flavonoids [33,34]. Of other studies $(n=10)$ evaluating the association with polyphenol subclasses, mainly total flavonoids showed that only 3 found a significant inverse association with CV events [33,35,36], with intake ranging from 115 to $944 \mathrm{mg} / \mathrm{day}$. In USA, an inverse association was observed for both $\mathrm{CV}$ and $\mathrm{T} 2 \mathrm{D}$ with the highest quartile of total flavonoids (585 mg/day) [35]. In Poland, total polyphenol intake, of $2632 \mathrm{mg} /$ day showed inverse association with risk of T2DM [37]. In a population-based study in Brazil, association between polyphenol intake and hypertension reported inverse association [38]. Both the Mediterranean and Japanese diets are known to be healthy, hence people of the Mediterranean countries enjoy a low risk of CVDs and diabetes, while Japanese are famous for their longevity. However, there are both similarities and discrepancies in intake of foods and beverages between the two diets. The Mediterranean diet is characterized by high consumption of cereals (wheat), vegetables and fruit, fish and olive oil [4]. Japanese also consume large amounts of grains (rice), vegetables and fruit, and fish, but lower intake of energy and fats [1-3]. It seems that the typical Mediterranean people take high amounts of total fats, mainly olive oil (approximately $100 \mathrm{~g} / \mathrm{day}$ in males and $80 \mathrm{~g}$ in females) and also polyunsaturated fatty acids [4]. In contrast, the traditional Japanese diet contains lower amount of fat, However, in the recent past there has seen a change from $20 \%$ energy from fats to $30 \%$, whereas the ratio of n-6 PUFAs/n-3 PUFAs has altered from 2-3 to 4-5, but there is no significant increase in CVDs [3]. It seems that a healthiest diet should have all the ten qualities of the diets [8] (Table 2).

Table 2: The ten qualities of the high quality foods

\begin{tabular}{|l|l|}
\hline Qualities of foods & Examples of foods \\
\hline 1.Low glycemic index & Nuts, vegetables, whole grains \\
\hline 2.Food diversity. & Whole grains, beans, vegetables \\
\hline 3.High nutrient density. & Nuts, vegetables, whole grains \\
\hline 4..No trans fat & Grilled foods, boiled foods \\
\hline 5. No/low sugar refined & Guava, apples, papaya, oranges \\
\hline 6.Low salt & Fruits, vegetables, nuts \\
\hline 7.Moderate healthy fat & Olive oil, mustard oil, nuts. \\
\hline 8.High fiber & Vegetables, whole grains, fruits \\
\hline 9.Beneficial effects on gut microbiota. & Vegetables, whole grains, fruits \\
\hline 10.Non per-oxidation of foods & Fresh foods, without frying. \\
\hline Foods requiring mastication & Whole grains, nuts, fruits, fish \\
\hline
\end{tabular}




\section{DETERMINANTS OF SUPERIORITY OF INDO-MEDITERRANEAN DIET}

The major constituents responsible for superiority of the Indo-Mediterranean diet are more of whole grains such as millets, porridge, beans, brown rice and spices; coriander, turmeric, fenugreek, cumin and cinnamon, peppers, onion, garlic, curd, butter milk, without animal foods, except fish, and other diets indicate that, it has all the ten special qualities [8, 39-41]. These characteristics of diets are not so much, in the Mediterranean and DASH diet as well as in the Japanese diet, due to presence, although low, of red meat, preserve meat, refined foods and egg in these diets [3-6]. The superiority of Indo-Mediterranean diet over other cardio-protective diets is also clear from randomized, controlled trials which found that treatment with such diets was associated with significant decline in CVDs including heart failure and arrhythmias as well as all-cause mortality [7-10]. Adverse effects of animal foods and refined foods have also been reported more recently in cohort studies [42].

The Indo-Mediterranean diet has no animal foods (except fish), lower saturated fat and total fat, salt and sugar but high omega-3 and flavonoids as well as other nitric oxide activating foods which may be protective against CVDs as well as other and diabetes [1-3, 6-13]. A Metaanalysis of studies relating to three randomized, controlled single blind trials on the role IndoMediterranean style foods and nutrients in the prevention of CVDs including heart failure has also been published [7]. These studies compared the intervention and control groups; for behavioral risk factors, food intakes, fatty acid intake and ratio of polyunsaturated fatty acid (PUFA)/flavonoid intake respectively in the two groups $(n=1,446$ vs 1,320$)$. The findings showed marked beneficial effects of Indo-Mediterranean style foods and nutrients, on heart failure and arrhythmias, almost similar to the Mediterranean diets. Indo-Mediterranean diet also included fish intake (100-150 g twice weekly) for non-vegetarians which has been found to reduce all-cause mortality [13]. Fruits and vegetable are rich sources of potassium, magnesium and fiber whereas whole grains such as beans and millets are rich in fiber, protein, polyphenolics and flavonoids, magnesium, calcium, iron and folic acid. These nutrients can also take care of the double burden of diseases [8-10]. It is clear that Indo-Mediterranean diet is superior to these diets because it has no animal foods, except fish and it has low glycemic index and high food diversity compared to all other protective diets. 
A large body of evidence has shown that a diet rich in healthy plant based foods and with fewer animal source foods; fish other sea foods and poultry; up to five servings of animal source foods per week, can confer both improved health and environmental benefits. These dietary patterns are commonly observed in all the protective diets; such as DASH and Mediterranean style diets and also in the Japanese diet [4-6]. Some experts believe that diet used in the Dietary Advice to Stop Hypertension (DASH) study may be superior to conventional Mediterranean diet [4-6,12]. The DASH diet is rich in vegetables, fruits, and low-fat dairy products, contains whole grains, fish, poultry, and nuts and limits saturated fat, red meat, sweets, and sugar-containing beverages [5,6]. Thus, this diet is comprised of lower amounts of total and saturated fat, and cholesterol while providing higher amounts of potassium, magnesium, calcium, fiber, and protein. Despite minor differences between DASH diet and Mediterranean diets, some studies have investigated other beneficial effects of this dietary pattern such as reducing insulin resistance and controlling fasting blood glucose and lipid profiles suggesting this dietary pattern, may also be useful for the prevention of CVDs and lipid profile [4-6,11,12].The traditional Mediterranean style diets focuses on a high intake of olive oil, fruits, nuts, vegetables, and grains; moderate intake of fish and poultry; low intake of dairy products, red meat, processed meat, and sweets; and moderate consumption of wine [4,17,18]. Randomized, controlled trials have found that increased adherence to the Mediterranean style diets resulted in a positive effect on CVD's risk and mortality [4].

In a systemic review, a total of 1 randomized clinical trial and 152 observational studies were included comprising of adults and older adults, aged 17-84 years from 28 countries with high or very high Human Development Index [19]. The findings suggested that dietary patterns (possibly rich in flavonoids), including higher intake of vegetables, fruits, legumes, nuts, whole grains, unsaturated vegetable oils, fish, and lean meat or poultry, were associated with a decreased risk of all-cause mortality. These healthy patterns were also relatively low in red and processed meat, high-fat dairy, and refined carbohydrates or sweets. Some of these dietary patterns also included intake of alcoholic beverages in moderation. It is possible that consuming a nutrient-dense dietary pattern was associated with reduced risk of death from all causes [19]. It seems that a high intake of fruits, vegetables, nuts, whole grains and olive oil that are rich sources of antioxidant nutrient, may reduce the risk of oxidative stress-related diseases [2, 4, 
20,21]. It is also possible that numerous individual functions of the nutrients, as well as their combined additive or synergistic effects are crucial to understand their beneficial effects on CVDs. A large majority of the phytochemicals present in the diets, are redox active molecules and therefore defined as antioxidants. It is possible that antioxidants originating from foods may work as antioxidants and anti-inflammatory agents in the body tissues, causing beneficial effects on CVDs, through other mechanisms, including acting as inducers of mechanisms related to antioxidant defense, DNA repair, and cell maintenance [20-30,43].

In view of the complex role of diet in CVDs and T2DM, it is challenging to point out a nutrient as cause of the disease because a typical diet provides more than 25,000 bioactive food constituents [28, 29], It seems that multiple nutrients may modify a multitude of processes that are related to these diseases. A recent study has reported that high-polyphenol Mediterranean diet in conjunction with moderate physical activity was associated with lower brain atrophy, indicating that these diets can prevent neurodegenerative diseases [44]. The Indo-Mediterranean diet appears to be more suitable for Sustainable Food Systems for Food Security and Nutrition of the FAO and UNO [45].

\section{Limitations:}

There are variations in studies regarding variety of flavonoids included in the studies from various countries, to establish the association of flavonoid intake with risk of CVDs. There are only two randomized trials with Indo-Mediterranean diet for prevention of CVDs [9,10], in contrast to other protective diets which have many studies to support their cardio-protective effects $[1,2,4-6,11,12]$. The standard diet in India provides hardly 600-700 mg/day of flavonoids which is inadequate for management of diseases and moreover, Indian take tea with milk which reduces the bioactivity of flavonoids. Another limitation is that the high content of flavonoids in the Indo-Mediterranean diet are because this diet was constructed for patients, but less commonly consumed, because of transition of the populations causing reduced intake of traditionalfoods.

In brief, there is substantial evidence that increased intake of Mediterranean type of diets can cause significant reduction in CVDs and diabetes. It is also clear that DASH diet has many similarities with Mediterranean type of diets without any emphasis on olive oil consumption, 
which can also decrease CVDs and diabetes. However, Japanese diet may be superior to Mediterranean type of diets and DASH diet, due to greater contents of antioxidant flavonoids, which is known to provide lower risk of CVD and diabetes as well as longevity. Finally, high content of flavonoids in the Indo-Mediterranean diet, similar to traditional Japanese diet (1800 vs $1500 \mathrm{mg} /$ day) respectively, indicate that this diet can play potential role in the management of CVDs and T2DM.The Indo-Mediterranean diet could be superior to DASH diet, Mediterranean diet as well as Japanese diets, due to greater food diversity and glycemic index but no unhealthy animal foods that are present in other diets. The high qualities of Indo-Mediterranean diet may be because of increased content of whole grains, millets, porridge and beans as well spices, which are not commonly found in other types of protective diets. The ten characteristics of a high quality diet that are present in the Indo-Mediterranean diet appear to be fundamental, for a better future; healthiness and healthy life expectancy and longevity.

\section{Conflicts of Interest: We declare no conflict of interest in our study}

\section{REFERENCES:}

1.Keys, A. Coronary Heart Disease in Seven Countries. Circulation 1970; 3, 1-211 2. Hertog MG, Kromhout D, Aravanis C, Blackburn H, Buzina R, Fidanza F, Giampaoli S, Jansen A, Menotti A, Nedeljkovic S, et al. Flavonoid intake and long-term risk of coronary heart disease and cancer in the seven countries study. Arch Intern Med. 1995 Feb 27;155(4):381-6. Erratum in: Arch Intern Med 1995 Jun 12;155(11):1184.

3.Abe S, Zhang S, Tomata Y, Tsuduki T, Sugawara Y, Tsuji I. Japanese diet and survival time: the Ohsaki cohort 1994 study. Clin Nutr. 2020;39(1):298-303

4.Estruch R, Ros E, Salas-Salvadó J, Covas MI, Corella D, Arós F, Gómez-Gracia E et al. for the PREDIMED Study Investigators. Primary prevention of cardiovascular disease with a Mediterranean diet supplemented with extra-virgin olive oil or nuts. N Engl J Med 2018; 378:e34.DOI: 10.1056/NEJM oa1800389

5. Rahimlou M, Grau N, Banaie-Jahromi N, Taheri M, Khosravi A, Mavrommatis Y, Mohammadifard N. Association of adherence to the dietary approach to stop hypertension and Mediterranean diets with blood pressure in a non-hypertensive population: Results from Isfahan Salt Study (ISS). Nutr Metab Cardiovasc Dis. 2022; Jan;32(1):109-116.

6.Zhang N, Xiao X, Xu J, Zeng Q, Li J, Xie Y, Guo B, Dai S, Zhu X, Lei Y, Duojizhuoma, Yin J, Zhao X; China Multi-Ethnic Cohort Study Collaborative Group. Dietary Approaches to Stop Hypertension (DASH) diet, Mediterranean diet and blood lipid profiles in less-developed ethnic minority regions. Br J Nutr. 2021; Oct 4:1-10.

7.Singh RB, Takahashi T, Fatima G, Horuichi R, Fedacko J, Huzova Z. Effects of antioxidant rich Indo-Mediterranean foods on pre-heart failure: results from the randomized controlled trials. The Open Jour of Inflammation 2020;8, DOI: 10.2174/1875041902008010001, 2020, 8, 1-10 
8. Singh RB, Watanabe $S$ and Isaza $A$. The ten qualities of a high quality diet? In editors, Functional Foods and Nutraceuticals in Metabolic and Non-communicable diseases. Elsevier, USA, 2022.

9.Singh RB, Dubnov G, Niaz MA,Ghosh S,Singh R,Rastogi SS,Manor O,Pella D, Berry EM. Effect of an Indo-Mediterranean diet on progression of coronary disease in high risk patients: a randomized single blind trial. Lancet 2002,360:1455-1461

10.Singh, RB;Rastogi, SS;Verma, R;Laxmi, B;Singh, R;Ghosh, S;Niaz, MA. Randomized, controlled trial of cardio protective diet in patients with acute myocardial infarction: results of one year follow up. BMJ, 1992, 304, 1015-9.

11.Zhou BF, Stamler J, Dennis B, Moag-Stahlberg A, Okuda N, Robertson C, Zhao L, Chan Q, Elliott P; INTERMAP Research Group. Nutrient intakes of middle-aged men and women in China, Japan, United Kingdom, and United States in the late 1990s: the INTERMAP study J Hum Hypertens. 2003 Sep;17(9):623-30. doi: 10.1038/sj.jhh.1001605.

12.Zhang R, Wang Z, Fei Y et al. The Difference in Nutrient Intakes between Chinese and Mediterranean, Japanese and American Diets. Nutrients 2015, 7, 4661-4688; doi:10.3390/nu 7064661

13.Burr ML, Fehily AM, Gilbert JF. Effects of changes in fat, fish and fiber intakes on death and myocardial infarction: Diet and Re-infarction Trial(DART). Lancet 1989;ii:757-61

14. Singh RB, Kartike K, Isaz A. Fish, fish oil and fish peptides and other sea foods. In Editors:

RB Singh, Shaw Watanabe, Adrian Isaza,. Functional Foods and Nutraceuticals in Metabolic and Non-communicable diseases. Elsevier, USA, 2022.Page 248.

15.Chibisov S, Kharlitskaya E, Singh RB. Polyphenols in health and diseases. In Editors: RB Singh, Shaw Watanabe, Adrian Isaza,. Functional Foods and Nutraceuticals in Metabolic and Non-communicable diseases. Elsevier, USA, 2022.Page 671..

16.Jan Fedacko1, Toru Takahashi2, Ram B. Singh et al Western diets and risk of noncommunicable diseases. In Editors: RB Singh, Shaw watanabe, Adrian Isaza, Functional Foods and Nutraceuticals in Metabolic and Non-communicable diseases. Elsevier, USA, 2022.Page 3. 17.Ogce F, Ceber E, Genc RE, Oran NT. Comparison of Mediterranean, Western and Japanese diets and some recommendations. Asian Pacific journal of cancer prevention: APJCP 2008; 9(2):351-6

18.Tokudome S, Okuyama H, Ichikawa S, Tokudome Y et al. The Mediterranean vs the Japanese diet. European Journal of Clinical Nutrition 2004; 58(9):1323; DOI:10.1038/sjEjcn. $\underline{1601970}$

19.English LK, Ard JD, Bailey RL, et al. Evaluation of Dietary Patterns and All-Cause Mortality: A Systematic Review. JAMA Netw Open. 2021;4(8):e2122277. doi:10.1001/jama networkopen.2021.22277

20.Bendokas V, Stanys V, Mažeikienè I, et al. Anthocyanins: From the Field to the Antioxidants in the Body. Special Issue "Antioxidants in Foods. Antioxidant 2020; Antioxidants 2020, 9(9), 819; https://doi.org/10.3390/antiox9090819 - 02 Sep 2020

21.Carlsen MH, Halvorsen BL, Holte K, et al. The total antioxidant content of more than 3100 foods, beverages, spices, herbs and supplements used worldwide. Nutr J. 2010; 9:3. Published 2010 Jan 22. doi:10.1186/1475-2891-9-3

22.Liu, J.; Hefni, M.E.; Witthöft, C.M. Characterization of Flavonoid Compounds in Common Swedish Berry Species. Foods 2020, 9, 358. https://doi.org/10.3390/foods9030358 
23. Sources of Flavonoids in the U.S. Diet Using USDA's Updated Database on the Flavonoid Content of Selected Foods. Haytowitz, D.B., Bhagwat, S., Harnly, J., Holden, J.M., Gebhardt, S.E. USDA, Agricultural Research Service, Beltsville Human Nutrition Research Center, Nutrient Data Laboratory and Food Composition Laboratory, Beltsville, MD 20705. https:// www.ars.usda.gov/ARSUserFiles/80400525/Articles/AICR06_flav.pdf, accessed January, 2022

24. Osborn LJ, Claesen J, and Brown JM. Microbial Flavonoid Metabolism: A Cardiometabolic Disease Perspective. Annual Review of Nutrition 2021;Vol. 41:433-454 (Volume publication date October 2021.

25. Micek A, Godos J, Del Rio D, Galvano F, Grosso G. Dietary flavonoids and cardiovascular disease: A Comprehensive Dose-Response Meta-Analysis. Molecular Nutrition 2021; 65: March 2021; 2001019

26. Parmenter BH, Croft KD, Hodgson JM, et al. An overview and update on the epidemiology of flavonoid intake and cardiovascular disease risk. Food Funct. 2020,11: 6777-6806

27. Guasch-Ferré M, Li Y, Willett WC et al. Consumption of Olive Oil and Risk of Total and Cause-Specific Mortality Among U.S. Adults JACC 2022; 79 (2):

28.Del Bo C, Bernardi S, Marino M, et al. Systematic review on polyphenol intake and health outcomes: Is there sufficient evidence to define a health-promoting polyphenol-rich dietary pattern?. Nutrients. 2019;11(6):1355. Published 2019 Jun 16. doi:10.3390/nu11061355

29. Escobar-Cévoli R, Castro-Espín C, Béraud V, Buckland G and Zamora-Ros R. An Overview of global flavonoid intake and its food sources. In: Chapter from the book Flavonoids - From Biosynthesis to Human Health, 2017; DOI: 10.5772/67655

30. Otaki N, Kimira M, Katsumata S, Uehara M, Watanabe S, Suzuki K. Distribution and major sources of flavonoid intakes in the middle-aged Japanese women. J Clin Biochem Nutr. 2009;44(3):231-238. doi:10.3164/jcbn.08-231

31.Miranda A.M., Steluti J., Fisberg R.M., Marchioni D.M. Association between polyphenol intake and hypertension in adults and older adults: A population-based study in Brazil. PLoS ONE. 2016;11:e0165791. doi: 10.1371/journal.pone.0165791.

32.Zamora-Ros R., Forouhi N.G., Sharp S.J., González C.A., Buijsse B., Guevara M., Van Der Schouw Y.T., Amiano P., Boeing H., Bredsdorff L., et al. The association between dietary flavonoid and lignan intakes and incident type 2 diabetes in European populations: The EPICInterAct study. Diabetes Care. 2013;36:3961-3970. doi: 10.2337/dc13-0877.

33. Jennings A., Spector T., Cassidy A., Macgregor A., Welch A.A. Intakes of anthocyanins and flavones are associated with biomarkers of insulin resistance and inflammation in women. $J$. Nutr. 2013;144:202-208. doi: 10.3945/jn.113.184358.

34. Ponzo V., Goitre I., Fadda M., Gambino R., de Francesco A., Soldati L., Gentile L., Magistroni P., Cassader M., Bo S. Dietary flavonoid intake and cardiovascular risk: A population-based cohort study. J. Transl. Med. 2015;13:218. doi: 10.1186/s12967-015-0573-2 
35.Wedick N.M., Pan A., Cassidy A., Rimm E.B., Sampson L., Rosner B., Willett W., Hu F.B., Sun Q., Van Dam R.M. Dietary flavonoid intakes and risk of type 2 diabetes in US men and women. Am. J. Clin. Nutr. 2012;95:925-933. doi: 10.3945/ajcn.111.028894.

36.Tresserra-Rimbau A., Medina-Remón A., Salas-Salvadó J., Estruch R., Lamuela-Raventós R.M., Rimm E.B., Ruiz-Gutiérrez V., Corella D., Sorlí J.V., Vinyoles E., et al. Inverse association between habitual polyphenol intake and incidence of cardiovascular events in the PREDIMED study. Nutr. Metab. Cardiovasc. Dis. 2014;24:639-647.

37.Grosso G., Stepaniak U., Micek A., Kozela M., Stefler D., Bobak M., Pajak A. Dietary polyphenol intake and risk of type 2 diabetes in the Polish arm of the health, alcohol and psychosocial factors in Eastern Europe (HAPIEE) study. Br. J. Nutr. 2017;118:60-68.

38. Miranda A.M., Steluti J., Fisberg R.M., Marchioni D.M. Association between polyphenol intake and hypertension in adults and older adults: A population-based study in Brazil. PLoS ONE. 2016;11:e0165791. doi: 10.1371/journal.pone.0165791.

39.Kumar A, Kumari P, and Kumar M. Role of millets in disease prevention and health promotion. In Editors: R B Singh, Shaw Watanabe, Adrian Isaza, Functional Foods and Nutraceuticals in Metabolic and Non-communicable Diseases. Elsevier, USA, 2022, Page 341.

40.Watanabe S, Takahashi M, Hashimoto H, Kikuchi K, Matsuo M and Otsubo K. Medical rice: discovery of a new food. In Editors: R B Singh, Shaw Watanabe, Adrian Isaza, Functional Foods and Nutraceuticals in Metabolic and Non-communicable Diseases. Elsevier, USA, 2022; Page 137.

41.De A K, and De M. Functional and therapeutic applications of some general and rare spices. In Editors: R B Singh, Shaw Watanabe, Adrian Isaza, Functional Foods and Nutraceuticals in Metabolic and Non-communicable Diseases. Elsevier, USA, 2022; Page 411

42.Zhong VW, Van Horn L, Greenland P, et al. Associations of processed meat, unprocessed red meat, poultry, or fish intake with incident cardiovascular disease and all-cause mortality. JAMA Intern Med. 2020;180(4):503-512.

43.Jennings A., Spector T., Cassidy A., Macgregor A., Welch A.A. Intakes of anthocyanins and flavones are associated with biomarkers of insulin resistance and inflammation in women. $J$. Nutr. 2013;144:202-208. doi: 10.3945/jn.113.184358.

44.Kaplan A, Zelicha H, Meir AY et al. The effect of a high-polyphenol Mediterranean diet (GREEN-MED) combined with physical activity on age-related brain atrophy: the DIRECT PLUS randomized controlled trial. Amer J Clin Nutr 2022; nqac001,

45.FAO, UNO. The State of Food and Agriculture: Sustainable Food Systems for Food Security and Nutrition. "http://www.fao.org/"http://www.fao.org/ docrep/ meeting/ 028/mg413e01 